\title{
REVISIÓN DEL TEXTO "CRÍTICA DEL DERECHO DEL TRABAJO" DE ALAIN SUPIOT"
}

\section{Patricia Fuenzalida MarTínez}

¿Por qué este comentario de un libro ya con muchos años de salir a la luz? La pregunta podría inmediatamente atacar al lector, pero sin duda, mi respuesta es que existen obras que, con la maceración intelectual propia del pensamiento crítico, nunca desaparecen y adquieren relevancia y recuerdo importante cuando se deben utilizar para provocar la recensión o el comentario. De ahí la necesaria "Re-Visión". Y lo advierto porque recientemente se ha ingresado al Congreso Nacional el Mensaje $N^{\circ} 1055-362$, mediante el cual se da inicio a la tramitación del Proyecto de Ley que Modifica el Sistema de Relaciones Laborales, Introduciendo Modificaciones al Código del Trabajo. Inmediatamente desde su anuncio, han aparecido un sinnúmero de voces que, desde distintos puntos de vista y defendiendo distintos intereses, han comentado el contenido del Proyecto y sus posibilidades de incidir positivamente en las relaciones laborales.

Ahora bien, más allá de los análisis específicos que se puedan hacer respecto de este Proyecto y su contenido, otra posibilidad es analizar en su conjunto las diversas reformas que se han venido introduciendo al Código del Trabajo y preguntarse si es posible identificar en ellas una finalidad común que las transforme en un cuerpo orgánico y armónico o si por el contrario, se trata de reformas separadas e independientes sin un hilo conductor que nos permita caracterizar a nuestra actual legislación laboral.

$\mathrm{Y}$ es en relación a este nivel de análisis que podemos volver sobre una de las obras de Alain Supiot, que pese a tener más de veinte años, sigue estando plenamente vigente al momento de analizar nuestras normas laborales, incluso desde su proceso de formación. En concreto nos referimos a la Crítica del Derecho del Trabajo, en que su autor plantea la existencia, en Europa, de dos visiones de la relación jurídica de trabajo, una proveniente de la cultura romanista, que la analiza como "una operación de intercambio entre sujetos formalmente iguales, es decir, sitúa esta relación en la órbita del derecho de obligaciones"2, destacando su carácter contractual; en tanto que la segunda, proveniente del derecho germánico, concibe "la relación laboral como una situación de pertenencia personal a una comunidad, y sitúa así esta relación en la órbita del estatuto de las personas"3.

Por otra parte, si consideramos que el origen del Derecho del Trabajo, se explica como "una solución defensiva del Estado liberal para, mediante la promulgación de normas protectoras de los trabajadores atender a la integración e institucionalización del conflicto entre trabajo asalariado y el capital en términos compatibles con la estabilidad del sistema económico establecido"4, concepto que efectivamente podemos extrapolar al desarrollo del Derecho del Trabajo en Chile, durante

\footnotetext{
1 Supiot, Alain. Critica del derecho del trabajo, Madrid, España: Ministerio del Trabajo y Asuntos Sociales Subdirección General de Publicaciones, 1996. pp. 29 y ss.

Abogado. Profesora de Derecho del Trabajo y de la Seguridad Social. Jueza Titular del Segundo Juzgado del Trabajo de Santiago.

$2 \quad$ Ibid, p. 32.

$3 \quad$ Ibid, p.34.

4 Palomeque, Manuel Carlos. Derecho del trabajo e ideología. Citado en: Ugarte, José Luis. El nuevo derecho del trabajo -3a edición-. Santiago, Chile: Legal Publishing, 2011. pp. 7 y 8.
} 
los inicios del siglo $\mathrm{XX}^{5}$, dando a luz un Derecho del Trabajo que nace y mantiene, por décadas, vinculado a la visión contractual.

En este contexto, las normas laborales morigeraron la legislación civil, que hasta la fecha regulaba el trabajo, consagrando la intervención estatal a fin de proteger al trabajador y se legitimando el actuar colectivo de aquellos, buscando mejorar la situación en que los trabajadores participan del intercambio, pero, todavía considerando al trabajo como un bien susceptible de ser transado. En efecto, nuestro actual artículo $7^{\circ}$ del $\mathrm{CT}$, describe a la relación laboral como una de tipo sinalagmáti$\mathrm{ca}$, en que una parte presta sus servicios personales a otra que lo remunera por ello, misma idea que encontramos en la Constitución Política de la República, cuyo artículo $19 \mathrm{~N}^{\circ} 16$, consagra el derecho a la libre contratación y la libre elección del trabajo con una justa remuneración, destacando la autodeterminación del individuo para otorgar su consentimiento a la realización de actos y contratos lícitos ${ }^{6}$.

Sin embargo, desde la década de 1990, tras el retorno a la democracia y a consecuencia de procesos tales como la revalorización de los derechos fundamentales, la constitucionalización de tales derechos, y quizás, también, en respuesta al retroceso que en la materia había supuesto el Gobierno Militar, al alero del Plan Laboral ${ }^{7}$ y a la precarización que importan los nuevos fenómenos laborales como la flexibilidad, subcontratación, tercerización, teletrabajo y otros, que atenúan la subordinación, el Derecho del Trabajo ha experimentado una fuerte "germanización".

Sostenemos aquello por cuanto, desde entonces, las reformas legales y las construcciones doctrinarias y jurisprudenciales, avanzan hacia un concepto de trabajador que deja de ser un mero oferente de mano de obra, para transformarse en un ciudadano que, con la dignidad y derechos que tal calidad importa, se integra a una empresa, que no es sino una proyección de la comunidad. Se admite la noción alemana de la horizontalidad de los derechos, que permite proyectar los derechos ciudadanos al interior del contrato de trabajo, como límites al poder del empleador, lo que da cuenta de que el trabajo es una actividad que se sitúa y explica dentro de una comunidad, que involucra íntegramente a la persona del ciudadano, quien se aporta a si mismo a la relación laboral, sin que ello pueda justificar la pérdida de dignidad o la "cosificación" del trabajador.

En efecto, podemos mencionar diversas reformas legales que han venido a reforzar este carácter del Derecho del Trabajo como un verdadero estatuto del trabajador. Entre ellas, encontramos un grupo que busca dotar de estabilidad al contrato de trabajo, cimentando las condiciones del surgimiento de una identidad social a través del contrato de trabajo ${ }^{8}$, a la vez que se mejora la protección del trabajador, tanto durante la vigencia del contrato, al sancionar el despido a sola voluntad del empleador o infundado, como en el período de desempleo ${ }^{9}$. Un segundo conjunto de normas, profundiza la libertad sindical, entendiendo que el contenido y alcances del trabajo, exceden del sólo interés de quienes figuran como contratantes y tiene, eminentemente, un contenido social y/o colectivo ${ }^{10}$. Un tercer grupo de reformas, son aquellas que

$5 \quad$ Lizama, Luis. "El derecho del trabajo chileno durante el siglo XX", en: Revista Chilena de Derecho del Trabajo y de la Seguridad Social, Volumen 2, N 4, pp. 11 y ss. Santiago, Chile: Facultad de Derecho, Universidad de Chile, 2011. pp. 11 y ss.

$6 \quad$ Irureta, Pedro. "Constitución y orden público laboral. Un análisis del art. $19 \mathrm{~N}^{\circ} 16$ de la Constitución chilena". En: Colección de Investigaciones Jurídicas $\mathrm{N}^{\circ} 9$ Santiago, Chile: Universidad Alberto Hurtado, Santiago, 2006, p. 61.

LIZAMA, Luis, op. cit. (n. 5), pp. 122 y ss.

Supiot, Alain, op. cit. (n. 1), p. 111.

Ejemplo; leyes 19.010 de 1990; 19.631 de 1999; 19.759 de 2001; y 19.728 de 2001.

10 Cabe destacar la ratificación de los Convenios 87 y 98 de la OIT, además de las leyes 19.049 de 1991; 19.069 de $1991 ; 19.759$ 
verdaderamente introdujeron el concepto de ciudadanía en la empresa a la legislación positiva, disponiendo una protección del trabajador que sobrepasa la sola prestación de servicios, reconociendo que el trabajador es, siempre y ante todo, persona. Así, se fija el respeto a la dignidad de la persona como estándar mínimo de todo contrato de trabajo y se incluyen cuestiones tales como la no discriminación, protección a la libertad sexual, a la honra del trabajador y su familia, indemnidad, entre otros ${ }^{11}$. Es este grupo de normas y los procedimientos asociados a ellas, los que permiten decir que la relación laboral, actualmente, no puede ser comprendida sólo como un contrato de contenido patrimonial, en términos romanistas, ya que es la ley, sin injerencia de la voluntad de las partes, la que asigna al empleador la protección del trabajador en los aspectos mencionados, trasladando su rol desde un "comprador" de servicios al de verdadero garante de principios democráticos.

En segundo término, encontramos que la doctrina laboral, además de desarrollar los alcances e implicancias de la legislación referida, ha venido profundizando la importancia en la relación laboral de lo que se conoce como el contenido ético jurídico del contrato, esto es, de los elementos de fidelidad y protección que derivan del reconocimiento y aplicación del principio de la buena fe, en razón del cual se impone a las partes una serie de obligaciones, aun sin necesidad de convenio previo que las determine, cuya naturaleza no puede ser explicada únicamente a la luz del derecho de obligaciones ${ }^{12}$. Entre estos deberes encontramos, durante la etapa de precontrato, el deber de información y transparencia, confidencialidad y secreto, rectitud y respeto al interés de la contraparte; durante la vigencia del contrato, las partes deben cumplir no sólo de acuerdo a lo estipulado, sino del modo más acorde a la naturaleza de la obligación, se mencionan el deber de diligencia, cooperación y confianza, respecto del trabajador, y el uso razonable de los poderes de corrección y disciplina, la protección, el dar ocupación efectiva, la información y formación, respecto del empleador; partes que igualmente deben actuar movidas por la buena fe luego de la terminación del contrato ${ }^{13}$. Tales deberes no son meras abstracciones o declaraciones de contenido programático, pudiendo, en su mérito, fundamentar o desvirtuarse un despido, e incluso servir de base a la obligación de indemnizar a la contraparte.

También nos permite afirmar la existencia de un estatuto del trabajador, la consideración de que la elección de acogerse o no a las normas que regulan el contrato de trabajo no queda entregada a la voluntad de las partes, justamente, porque existe un interés social o comunitario, que se valora como superior al interés de los contratantes, en que todo trabajador cuente con aquella protección establecida en su calidad de tal, por ello, se establece como primer derecho irrenunciable, y en este sentido, norma básica del estatuto, la irrenunciabilidad de la calificación de un vínculo como laboral si se cumplen los presupuestos legales para ello, lo que explica la presunción de laboralidad contenida en el artículo $8^{\circ}$ del CT ${ }^{14}$.

Como venimos sosteniendo, el foco de la legislación laboral ha venido transitando desde una concepción más bien individualista, con preminencia del contrato individual y la libertad

\footnotetext{
de 2001; 20.057 de 2005 .

1 Ratificación de los Convenios 100 y 111 de la OIT, y leyes 19.591 de 1998; 20.005 de 2005; 20.087 de 2006; 20.248 de 2009, entre otras.

12 SupIot, Alain, op. cit. (n. 1), p. 45.

13 Irureta, Pedro. "Vigencia del principio de la buena fe en el derecho del trabajo chileno". en: Revista Ius et Praxis, Año 17, $N^{\circ} 2$, p. 160 y ss. Santiago, Chile: Facultad de Derecho, Universidad de Talca, 2011.

14 Sierra, Alfredo. "La teoría de los actos propios en el ámbito laboral". En: Cuadernos de Extensión Jurídica, No 18. Universidad de Los Andes. Santiago, Chile: 2010, p. 143 y ss.
} 
de las partes, que sólo fijaba mínimos irrenunciables o inderogables in pejus en materias muy acotadas, como salario mínimo y jornada, hacia una concepción más colectiva, que incorpora en su esfera de protección a los derechos fundamentales de los trabajadores, entendidos como valores o principios que toda la sociedad tiene interés en defender, reconociendo, además, que la vulneración de uno de ellos, en la mayoría de los casos, no sólo afecta a su víctima inmediata, sino también a otros trabajadores, en cuanto, a lo menos, disminuye la eficacia protectora de la norma. Así por ejemplo, el art. $486 \mathrm{del} \mathrm{CT,} \mathrm{toma} \mathrm{la} \mathrm{opción} \mathrm{por} \mathrm{la} \mathrm{protección} \mathrm{colectiva} \mathrm{de} \mathrm{los} \mathrm{dere-}$ chos fundamentales, legitimando activamente a "cualquier trabajador u organización sindical que, invocando un derecho o interés legítimo, considere lesionados derechos fundamentales..., para ejercer la acción prevista en el artículo 485 del mismo cuerpo legal, norma que tiene su correlato en el artículo 495 del CT, que consigna las medidas reparatorias como uno de los elementos que debe tener la sentencia que se dicte en procedimiento de tutela laboral, las que, en la práctica suelen exceder del trabajador individualmente considerado, como cuando se dispone la publicación o entrega de copias de la sentencia a los demás trabajadores, como medio de restablecer su confianza en la eficacia del Derecho del Trabajo.

Este enfoque en lo colectivo lo encontramos también en el Proyecto de Reforma contenido en el Mensaje $\mathrm{N}^{\circ} 1055-362$, y no sólo porque este corresponde a un proyecto de reforma a normas colectivas del Código del Trabajo, sino por los fines que se pretenden alcanzar. En el referido Mensaje se alude una y otra vez al sentido democratizador de la iniciativa, destacando aspectos como “... el interés creciente de los ciudadanos, que esperan poder participar de manera más vierta y propositiva en los temas que les interesan y que finalmente les afectan", y valores como el diálogo social; se pretende promover y facilitar la negociación colectiva en tanto ella constituye "una herramienta de participación, de reconocimiento social de los trabajadores... manifestación de la sociedad democrática... instrumento clave para promover la no discriminación y la igualdad". En definitiva, con este Proyecto se pretende obtener beneficios que exceden de las partes involucradas en el contrato de trabajo, destacando el rol que cumple la negociación colectiva para construir una sociedad más democrática y participativa, donde los conflictos puedan ser debidamente canalizados, desarrollándose de manera constructiva entre partes dotadas de una mayor igualdad, todo esto en un contexto de "equilibrio entre respeto de derechos y conciencia de deberes y, en consecuencia, un compromiso común y recíproco de trabajadores y empleadores respecto del destino de la empresa".

En conclusión, podemos afirmar que tal y como ha venido con otras reformas previas al Código del Trabajo, esta también sitúa a la relación laboral como una situación de pertenencia a la comunidad, destacando el nexo que existe entre la forma en que desarrollen las relaciones al interior de la empresa con la forma en que se desarrollan las relaciones en la sociedad, de modo que un sistema de relaciones laborales más democrático y participativo es requisito de una sociedad más democrática y participativa, reconociendo y fomentando la posibilidad de una participación propositiva y constructiva, no sólo en la comunidad nacional, sino también en la más pequeña comunidad laboral.

\section{BIBLIOGRAFÍA}

Supiot, Alain. Crítica del derecho del trabajo. Madrid, España: Ministerio del Trabajo y Asuntos Sociales Subdirección General de Publicaciones, 1996.

Ugarte, José Luis. El nuevo derecho del trabajo 3ª edición. Santiago, Chile: Legal Publishing, 2011. 
LızAma, Luis. "El derecho del trabajo chileno durante el siglo XX, en: Revista Chilena de Derecho del Trabajo y de la Seguridad Social, Volumen 2, $N^{\circ} 4$, pp. 11 y ss. Santiago, Chile: Facultad de Derecho de la Universidad de Chile, 2011.

IRURETA, Pedro. "Constitución y orden público laboral. Un análisis del art. $19 \mathrm{~N}^{\circ} 16$ de la Constitución chilena". En: Colección de Investigaciones Jurídicas $\mathrm{N}^{\circ}$ 9. Santiago, Chile: Universidad Alberto Hurtado, Santiago, 2006 